\title{
Value of High-Dose Cytarabine During Interval Therapy of a Berlin-Frankfurt-Munster-Based Protocol in Increased- Risk Children With Acute Lymphoblastic Leukemia and Lymphoblastic Lymphoma: Results of the European Organization for Research and Treatment of Cancer $\mathbf{5 8 8 8 1}$ Randomized Phase III Trial
}

\author{
By F. Millot, S. Suciu, N. Philippe, Y. Benoit, F. Mazingue, A. Uyttebroeck, P. Lutz, F. Mechinaud, A. Robert, P. Boutard, \\ G. Marguerite, A. Ferster, E. Plouvier, X. Rialland, C. Behard, D. Plantaz, M.F. Dresse, P. Philippet, L. Norton, A. Thyss, \\ N. Dastugue, C. Waterkeyn, E. Vilmer, and J. Otten for the Children's Leukemia Cooperative Group of the European \\ Organization for Research and Treatment of Cancer
}

Purpose: The European Organization for Research and Treatment of Cancer 58881 study was designed to test in a prospective multicentric randomized trial the value of high-dose (HD) intravenous (IV) cytarabine (Ara-C) added to HD IV methotrexate (MTX) to reduce the incidence of CNS and systemic relapses in children with increased-risk acute lymphoblastic leukemia (ALL) or stage III and IV lymphoblastic lymphoma treated with a Berlin-Frankfurt-Munster (BFM)-based regimen.

Patients and Methods: After completion of induction-consolidation phase, children with increased-risk (risk factor > 0.8 or T-lineage) ALL or stage III and IV lymphoblastic lymphoma were randomized to receive four courses of HD MTX $\left(5 \mathrm{~g} / \mathrm{m}^{2}\right.$ over 24 hours every 2 weeks) and four intrathecal administrations of MTX (Arm A) or the same treatment schedule with additional HD IV Ara-C $\left(1 \mathrm{~g} / \mathrm{m}^{2}\right.$ in bolus injection 12 and 24 hours after the start of each MTX infusion) (Arm B).

Results: Between January 1990 and January 1996, 653 patients with ALL (593 patients) or lymphoblastic lymphoma (60 patients) were randomized: 323 were assigned to Arm A (without Ara-C) and 330 to Arm B

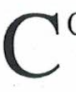
IOMBINATION OF high-dose (HD) intravenous (IV) methotrexate (MTX) and intrathecal (IT) chemotherapy without cranial irradiation has been widely accepted for protection from CNS relapse in children receiving intensive chemotherapy for non-high-risk acute lymphoblastic leukemia (ALL) ${ }^{1-3}$ In such patients, the rate of CNS relapses is $1.1 \%$ to $6.3 \%{ }^{2,4,5}$ The addition of $\mathrm{HD}$ cytarabine (Ara-C) (with Ara-C). A total of 190 events ( 177 relapses and 13 deaths without relapse) were reported, and the median follow up was 6.5 years (range, 2 to 10 years). The incidence rates of CNS relapse were similar in both arms whether isolated $(5.6 \%$ and $3.3 \%$, respectively) or combined $(5.3 \%$ and $4.6 \%$, respectively). The estimated 6-year disease-free survival (DFS) rate was similar (logrank $P=.67$ ) in the two treatment groups: $70.4 \%$ (SE = $2.6 \%)$ in Arm A and $71.0 \%(S E=2.5 \%)$ in Arm B. The 6-year DFS rate was similar for ALL and LL patients: $70.2 \%(\mathrm{SE}=1.9 \%$ ) versus $76.3 \%$ (SE $=5.6 \%)$.

Conclusion: Prevention of CNS relapse was satisfactorily achieved with HD IV MTX and intrathecal injections of MTX in children with increased-risk ALL or stage III and IV lymphoblastic lymphoma treated with our BFM-based treatment protocol in which cranial irradia" tion was omitted. Disappointingly, with the dose schedule used in this protocol, HD Ara-C added to HD MTX, although well tolerated, failed to further decrease the incidence of CNS relapse or to improve the overall DFS.

$J$ Clin Oncol 19:1935-1942. (2001 by American Society of Clinical Oncology.

to this prophylactic schedule may be useful to lower the incidence of CNS relapses because of in vitro antileukemic synergistic effect of Ara-C in combination with $\mathrm{MTX}^{6,7}$ and good penetration of systemic HD Ara-C in CNS of leukemic patients. $^{8,9}$ However, in the late 1980 s, no data were available on the clinical benefit of the addition of $\mathrm{HD}$ Ara-C. For this reason, the European Organization for
From the Departments of Pediatrics, University Hospitals of Poitiers, Lyon, Lille, Strasbourg, Nantes, Paris (Hospital R. Debré), Toulouse, Caen, Montpellier, Besançon, Angers, Reims, and Grenoble, France, and Verviers, Gent, and Brussels (Hospital Reine Fabiola, Akademish Ziekenhuis Vreije Universitijt Brussel), Belgium; Department of Pediatrics, University Hospital of Porto, Portugal; Laboratory of HematologyCytology, University Hospital of Toulouse, France; and the European Organization for Research and Treatment of Cancer Data Center, Brussels, Belgium.

Submitted July 18, 2000; accepted December 27, 2000.
Supported by grant nos. 5U10-CA11488-20 through 5U10CA11488-29 from the National Cancer Institute.

The contents of this publication are solely the responsibility of the authors and do not represent the official views of the National Cancer Institute.

Address reprint requests to F. Millot, MD, Department of Hematology and Medical Oncology, University Hospital of Poitiers, 350 Ave Jacques Coeur, BP 557-86021 Poitiers Cedex, France; email: f.millot@chupoitiers.fr.

(C) 2001 by American Society of Clinical Oncology.

0732-183X/01/1907-1935 


\section{6}

Research and Treatment of Cancer (EORTC) Children's Leukemia Cooperative Group (CLCG) conducted a randomized trial to assess the value of HD Ara-C in combination with HD MTX and IT chemotherapy to reduce the incidence of CNS and systemic relapses in children with increased-risk ALL and advanced-stage lymphoblastic lymphoma treated with a Berlin-Frankfurt-Munster (BFM)based regimen.

\section{PATIENTS AND METHODS}

\section{Patients}

In July 1989, the EORTC-CLCG instituted a treatment protocol (EORTC 58881) for patients younger than 18 years of age with previously untreated ALL or lymphoblastic lymphoma. Patients with mature B-cell ALL or mature B-cell lymphoma were not eligible. A of 28 centers from France, Belgium, and Portugal participated in his trial. According to their presenting features and the response to treatment, patients were stratified into three groups: low-risk, increased-risk, or very high-risk group. Low-risk group included leukemic patients with low tumor burden, defined as BFM risk factor (RF) calculated as $R F=0.2 \times \log _{10}$ [blast cell count $\left./ \mathrm{mm}^{3}+1\right]+0.06 \times$ $\mathrm{cm}$ of palpable liver $+0.04 \times \mathrm{cm}$ of palpable spleen) less than 0.8 and patients with stage I or II lymphoblastic lymphoma. Increased-risk group comprised ALL children with $R F \geq 0.8$, patients with $\mathrm{T}$-cell lineage ALL, and patients with stage III or IV lymphoblastic lymphoma. Very high-risk (VHR) group included children with at least one of the following criteria: more than $1 \times 10^{9} / \mathrm{L}$ blasts in peripheral blood the first week of prednisolone treatment and IT MTX at the end of the frst week undifferentiated leukemia features, presinjection, presence of acute undifferin in leukemic cells, absence of ence of $\mathrm{t}(4,11)$ or $\mathrm{t}(9,22)$ translocation in leuke for lymphoblastic lymphoma patients, after completion of induction therapy. Increased-risk patients, without VHR features, were the subjects of the present study. Permission to include each child in the study was obtained by informed consent from the parents. The respective institutional review boards approved the protocol.

\section{Definitions and Evaluations}

When bone marrow involvement was observed, patients with less han $25 \%$ blasts in a bone marrow aspirate and none in the peripheral considered to have lymphoma. Patients with lymphoblastic blood were conside lymphoma were staged according 10 . Mes specific clinical and imaging criteria. All cases werphologic characterislymphoblastic cell characteristics, inctic features. Morphologic classitics, immunophenotype, and cytogerishfication of the ALL was based on criterion lymphomas was performed American classification. ${ }^{11}$ Classification of the Revised Europeanaccording to the Working Formulation ${ }^{12,13}$ Frozen specimens or cell American Lymphoma Classification. ${ }^{12}$ Frozen specimen on suspensions were evaluated for B- and T-lineage ${ }^{14,15}$ Results were using standard techniques as previously reported. ${ }^{14}$. Results werticular considered positive if more than $30 \%$ of the cells expressed particular antigen. Cytogenetic analysis of the lymphoblastic cells was performed by $\mathrm{R}$ or $\mathrm{G}$ banding, and chromosomes were classified according International System for Human Cytogenetic defined as less than 5\%

For ALL, complete remission (CR) was defnermal hematopoiesis, absence of blasts in peripheral blood, and no evidence of disease at any ther site. For lymphoblastic lymphoma, CR was defined by the disappearance of all clinical, imaging, and cytologic signs of lymphoma, and good partial response was defined by the persistence of a the main diameter of which could not esidual mass in one tumor siameter. Results of treatment were evaluated exceed $30 \%$ of the initial diam at completion

nance phases.

CNS leukemia was diagnosed when neurologic abnom an when blasts to blastic infiltration of the CNS were observed CSF in which the were identified on cytocentrifuge examination count and differential WBC count was greater than 5 cells/ $\mu \mathrm{L}$. A CSF count and differial after cytocentrifugation were performed at the CSF analyses were not tration of IT MTX. Routine surveillance of CSF andysere but in case of performed during maintenance the of systemic relapse. Infecappearance of CNS symptoms or in casicies induced by the treatment tious, renal, hepatic, and neurologic toxicities ind Health Organization were evaluated and graded according to the grading system. ${ }^{17}$ Hepatic and renal toxicities werinine levels greater fined as an increase in serum trans than $1.25 \times$ upper normal limit.

\section{Treatment}

We used a BFM modified treatment protocol, but cranial irradiation 5 treatment protocol for the increased-risk patients is . In brief, after 1 week of prednisolone and one IT injection of MTX, all patients received induction therapy (daily prednisolone, weekly vincristine and daunorubicin, L-asparaginase twice weekly, and two IT injections of MTX) over a period of 4 weeks. During induction, the patients were randomized to receive Escherichia coli or Erwinia L-asparaginase (the dose for E coli and Erwinia preparations was the same in both arms). Patients with ALL or lymphoblastic lymphoma who achieved a CR and patients with ymphoblastic lymphoma who achieved a good partial response received 4 weeks of consolidation therapy (daily mercaptopurine, four 4-day courses of Ara-C, two courses of cyclophosphamide, and two IT injections of MTX). After consolidation therapy, patients in complete remission were assigned randomly to CNS prophylaxis regimen (interval therapy) with HD MTX alone (arm A) or HD MTX in combinationwith Ara-C (arm B). In arm A, patients received daily 6-mercaptopurine $\left(25 \mathrm{mg} / \mathrm{m}^{2}\right)$ and four courses of HD MTX ( $5 \mathrm{~g} / \mathrm{m}^{2}$ every 2 weeks). HD MTX was given as a 24-hour IV infusion with alkaline hydrach Intrathecal administration of MTX was perform ${ }^{2}$ given orally every 6 MTX infusion. Folinic acid rescue (15 mg/m given infusion and was hours) was initiated 12 hours after the end of MTX infusion and $10^{-6}$ continued until the MTX plasma concentration wV HD Ara-C $\left(1 \mathrm{~g} / \mathrm{m}^{2}\right.$ as a 10-minute infusion) administered 12 and 24 hours after the start of each MTX infusion. Each course of MTX or MTX in combination with Ara-C was started if the WBC count was above $2 \times 10^{9} / \mathrm{L}$ with more than $0.5 \times 10^{9} / \mathrm{L}$ polymorphonuclear cell and the platelet count above $50 \times 10^{9} / \mathrm{L}$. According to the protocol, lower dose of Ara-C $(2 \times 750$ $\mathrm{mg} / \mathrm{m}^{2}$ ) was administered in case of hematologic toxicity resulting in a delay of more than 7 days to perform the subsequent course of MTX Ara-C. Interval therapy was followed by a delayed intensification phase consisting of dexamethasone for 3 weeks, four weekly injections of vincristine and doxorubicin, and four injections of L-asparaginase followed by daily thioguanine (for 14 days), one course of cyclophosphamide, two 4-day courses of Ara-C, and one IT injection of MTX. Patients remaining in $\mathrm{CR}$ were randomized to receive maintenance treatment consisting of daily 6-mercaptopurine and weekly oral MTX 
VALUE OF HD ARA-C IN CHILDHOOD ALL AND LL

Table 1. Treatment Schedule for Increased-Risk Patients According to EORTC 58881 Profocol

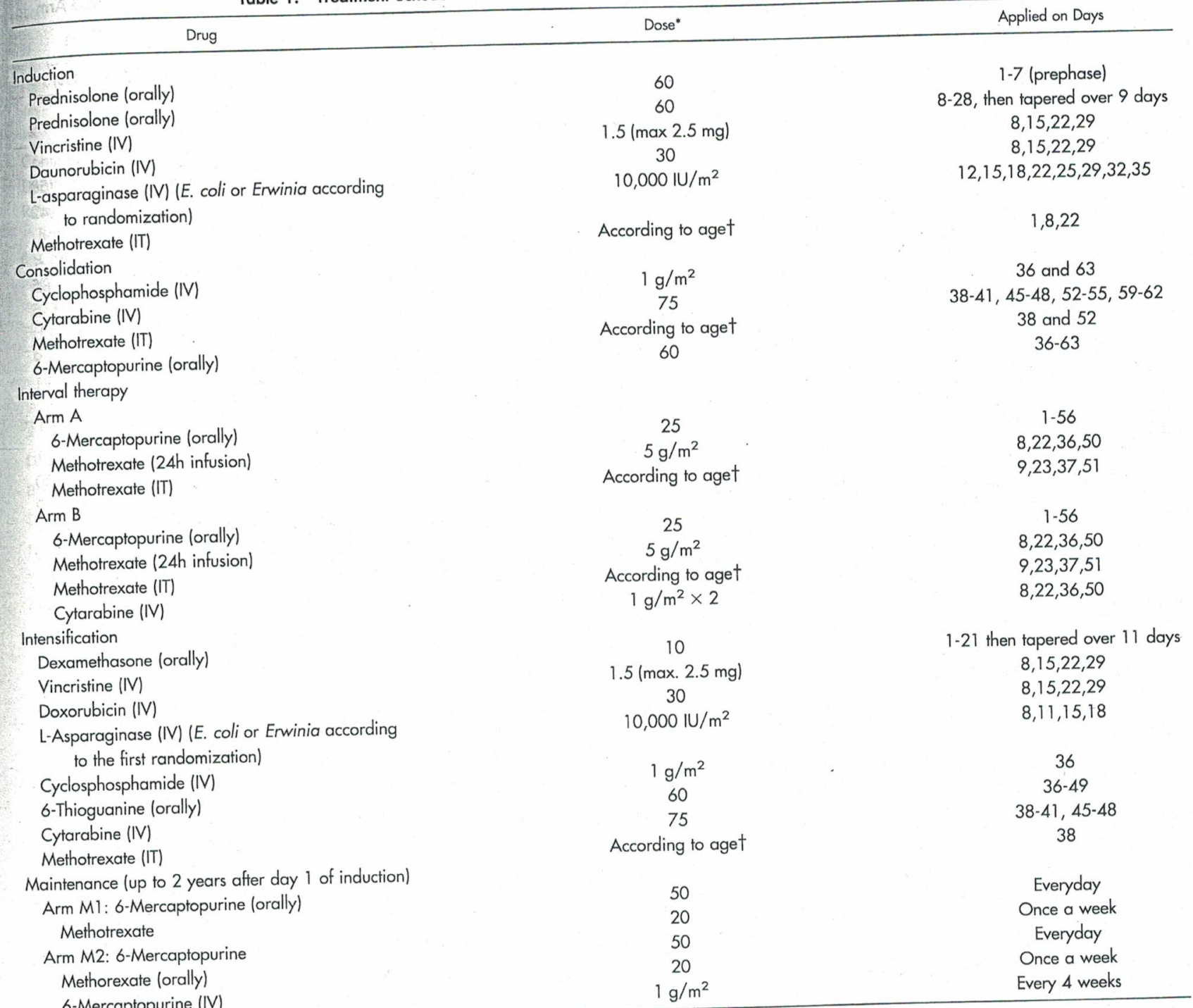
6-Mercaptopurine (IV)

*Unless otherwise indicated, doses are given in milligrams per meters squared.

thess than 1 year: $6 \mathrm{mg}$; 1 year: $8 \mathrm{mg}$; 2 years: $10 \mathrm{mg} ; 3$ years and more: $12 \mathrm{mg}$

or the same treatment with monthly IV 6-mercaptopurine. No cranial irradiation was performed. The total duration of the treatment protocol was 2 years.

\section{Statistical Considerations}

Randomization was performed centrally (EORTC Data Center, Brussels, Belgium) just before interval therapy treatment and was stratified according to center, $\mathrm{RF}(<0.8,0.8$ to $1.19 v \geq 1.2)$, and previous randomized arm (E coli or Erwinia L-asparaginase). The primary end point was the disease-free survival (DFS) from the date of randomization until the date of first relapse or until death in CR. The secondary end points were the time to CNS relapse (time from randomization until CNS isolated or combined relapse, where patients with other types of relapse were censored at the moment of relapse) and the duration of survival (the time from randomization until death, whatever the cause). The actuarial curves were computed using the Kaplan-Meier technique, and the SEs of the estimates were obtained via the Greenwood formula. ${ }^{18}$ The differences between curves were tested for statistical significance using the two-tailed log-rank test or the log-rank test stratified by a categorical factor. ${ }^{18}$ To summarize the overall treatment difference, the hazards ratio (HR) of having an event per time in arm B versus the one in arm A, along with its $95 \%$ confidence interval, was estimated via the Cox's proportional hazards model. ${ }^{19} \mathrm{~A}$ total of 592 patients were initially planned to be randomized to detect a significant difference in terms of DFS at 5 years $(70 \%$ $v 80 \%$ ), corresponding to a hazards ratio of 0.63 (alpha $=5 \%$, beta $=$ $20 \%$ ); a total of 148 patients had to be followed until relapse or death in first CR before the final analysis. All analyses were performed 
MILLOT ET AL

according to the intent-to-treat-principle. The Wilcoxon rank test was used for the treatment comparison regarding the duration of interval therapy. The rate of patients with an interval therapy exceeding 8 weeks was compared using the usual $\chi^{2}$ test. The $\chi^{2}$ from linear trend was used to compare the incidence of toxicities (graded as $0 v 1$ to $2 v 3$ to 4) in the two treatment arms.

\section{RESULTS}

\section{Patients}

Between January 1990 and January 1996, 27 centers of the EORTC-CLCG randomized a total of 656 patients to receive interval therapy with or without IV HD Ara-C. Two patients who were considered ineligible (one did not reach $\mathrm{CR}$ and one relapsed before randomization) and one who was considered unassessable (due to insufficient information about eligibility characteristics) have been excluded from further analyses. Among the remaining 653 patients, 323 were assigned to arm A (without Ara-C) and 330 to arm B (with Ara-C). Patient characteristics according to the treatment arm are listed in Table 2 . There were 60 patients (39 boys and 21 girls; 12 months to 16 years old; median age, 7 years) with lymphoblastic lymphoma (42 patients with Murphy stage III and 18 patients with stage IV disease) and 593 ALL patients ( 343 boys and 250 girls; 3 months to 17 years old; median age, 4 years). Among the latter group there were 19 patients ( 7 in arm A and 12 in arm B) with RF less than 0.8. Patient characteristics were well balanced in the two treatment arms. The type of L-asparaginase administered during the induction and consolidation phase or the type of maintenance (with or without IV 6-mercaptopurine) were well balanced in the two treatment groups as well (data not shown).

\section{Treatment Outcome}

At the time of final analysis, the median follow-up was 6.5 years (range, 2 to 10 years), and 190 events (comprising 177 relapses and 13 deaths in first CR) were reported. Site-specific relapse rates are listed in Table 3 according to the arm of randomization. The distribution of the relapse sites was similar in the two treatment groups. Isolated bone marrow relapse was the main cause of treatment failure in both arms (12.4\% and 14.3\%). In arm A and arm B, the incidences of CNS relapses were quite similar, whether isolated $(5.6 \%$ and $3.3 \%$, respectively) or combined $(5.3 \%$ and $4.6 \%$, respectively). Three patients $(0.9 \%)$ in arm A and $10(3 \%)$ in Arm B died while in CR as a result of the treatment toxicity (mainly infection). Four patients died (one in $\operatorname{arm} \mathrm{A}$ and three in $\operatorname{arm} \mathrm{B}$ ) during intensification phase, eight patients died (one in arm A and seven in arm B) during maintenance therapy, and only one patient died (in $\operatorname{arm}$ A) during interval therapy.
Table 2. Patient Characteristics According to the Randomized Arm

\begin{tabular}{|c|c|c|c|c|}
\hline & \multicolumn{2}{|c|}{$\begin{array}{c}\text { Arm A } \\
\text { (without Ara-C) } \\
(n=323)\end{array}$} & \multicolumn{2}{|c|}{$\begin{array}{c}\text { Arm B } \\
\text { (with Ara-C) } \\
(\mathrm{n}=330)\end{array}$} \\
\hline & $\begin{array}{l}\text { No. of } \\
\text { Patients }\end{array}$ & $\%$ & $\begin{array}{l}\text { No. of } \\
\text { Patients }\end{array}$ & $\%$ \\
\hline \multicolumn{5}{|l|}{ Sex } \\
\hline Male & 190 & 59 & 202 & 58 \\
\hline Female & 133 & 41 & 144 & 42 \\
\hline \multicolumn{5}{|l|}{$\begin{array}{l}\text { Female } \\
\text { Age }\end{array}$} \\
\hline$<1$ years & 7 & 2 & 1 & $<1$ \\
\hline 1.9 years & 266 & 82 & 280 & 85 \\
\hline $10-18$ years & 50 & 15 & 49 & 15 \\
\hline \multicolumn{5}{|l|}{$\begin{array}{l}\text { 10- } 18 \text { years } \\
\text { Disease }\end{array}$} \\
\hline LL & 31 & 10 & 29 & 9 \\
\hline ALL & 292 & 90 & 301 & 91 \\
\hline \multicolumn{5}{|l|}{ ALL patients only } \\
\hline \multicolumn{5}{|l|}{ WBC } \\
\hline$<25 \times 10^{9} / \mathrm{L}$ & 160 & 55 & & 61 \\
\hline $\begin{array}{l}25-100 \times 10^{9} / \mathrm{L} \\
\geq 100 \times 10^{9} / \mathrm{L}\end{array}$ & 97 & $\begin{array}{l}33 \\
12\end{array}$ & $\begin{array}{l}91 \\
28\end{array}$ & $\begin{array}{r}30 \\
0\end{array}$ \\
\hline $\begin{array}{l}\quad \geq 100 \times 10^{9} / \mathrm{L} \\
\mathrm{RF}\end{array}$ & 35 & \multicolumn{3}{|c|}{$\mathrm{RF}$} \\
\hline $\begin{array}{l}\text { RF } \\
<0.8\end{array}$ & 7 & 2 & 12 & 4 \\
\hline $0.8-1.19$ & 157 & 54 & 158 & 52 \\
\hline$\geq 1.2$ & 128 & 44 & 131 & 44 \\
\hline CNS involvement & 1 & $<1$ & 0 & 0 \\
\hline B lineage & $\begin{array}{r}258 \\
34\end{array}$ & $\begin{array}{l}88 \\
12\end{array}$ & $\begin{array}{r}230 \\
46\end{array}$ & $\begin{array}{l}85 \\
15\end{array}$ \\
\hline $\begin{array}{c}\text { T lineage } \\
\text { Chromosome }\end{array}$ & 34 & \\
\hline $\begin{array}{l}\text { Chromosome } \\
\text { findings }\end{array}$ & \multicolumn{4}{|c|}{$\begin{array}{l}\text { Chromosome } \\
\text { findings }\end{array}$} \\
\hline Successful & 206 & 64 & 219 & 66 \\
\hline \multicolumn{5}{|l|}{$\begin{array}{l}\text { Successful } \\
\text { examination }\end{array}$} \\
\hline $\begin{array}{l}\text { Diploid } \\
\text { Pseudodiploid }\end{array}$ & $\begin{array}{l}69 \\
34\end{array}$ & 17 & 57 & $\begin{array}{l}30 \\
26\end{array}$ \\
\hline $\begin{array}{l}\text { Pseudodiploid } \\
\text { Hypodiploid }\end{array}$ & $\begin{array}{r}34 \\
8\end{array}$ & 4 & 14 & 7 \\
\hline Hyperdiploid & 26 & 13 & 19 & 9 \\
\hline \multicolumn{5}{|l|}{$47-50$} \\
\hline Hyperdiploid & 65 & 32 & 49 & 23 \\
\hline \multicolumn{4}{|l|}{$\begin{array}{l}\text { Hyperdiploid } \\
51-66\end{array}$} & \\
\hline Other & 4 & & 3 & 1 \\
\hline
\end{tabular}

*Percentages were computed for those with a successful cytogenetic examination.

Considering the time-to-event analysis, the estimated 6-year DFS rate was $70.4 \%(\mathrm{SE}=2.6 \%)$ for the patients assigned to $\operatorname{arm~} \mathrm{A}$ and $71.0 \%(\mathrm{SE}=2.5 \%)$ for those assigned to arm B (Fig 1). The estimated hazards ratio was 1.06 (95\% confidence interval, 0.8 to 1.41 ). The log-rank test yielded a nonsignificant result $(P=.67)$. Because of the good balance of different features in the two treatment groups, these findings were not influenced when the treatment comparison was stratified by the initial WBC count, risk factor, immunophenotyping, or disease (data not shown). The 6-year DFS rate was similar for ALL and LI patients: $70.2 \%(\mathrm{SE}=1.9 \%)$ versus $76.3 \%(\mathrm{SE}=5.6 \%)$ 
Table 3. Outcome According to the Randomized Arm

\begin{tabular}{|c|c|c|c|c|}
\hline & \multicolumn{2}{|c|}{$\begin{array}{c}\text { Arm A } \\
\text { (without Ara-C) } \\
(\mathrm{n}=323)\end{array}$} & \multicolumn{2}{|c|}{$\begin{array}{c}\text { Arm B } \\
\text { (with Ara-C) } \\
(\mathrm{n}=330 \text { ) }\end{array}$} \\
\hline & $\begin{array}{l}\text { No. of } \\
\text { Patients }\end{array}$ & $\%$ & $\begin{array}{l}\text { No. of } \\
\text { Patients }\end{array}$ & $\%$ \\
\hline Continuous CR & 230 & 71.2 & 233 & 70.6 \\
\hline Death in CR & 3 & 0.9 & 10 & 3.0 \\
\hline Relapse & 90 & 27.9 & 87 & 26.4 \\
\hline Bone marrow, isolated & 40 & 12.4 & 47 & 14.3 \\
\hline CNS, isolated & 18 & 5.6 & 11 & 3.3 \\
\hline CNS, combined & 17 & 5.3 & 15 & 4.6 \\
\hline Other isolated & 10 & 3.1 & 7 & 2.1 \\
\hline Other combined & 5 & 2.0 & 7 & 2.1 \\
\hline
\end{tabular}

The type of L-asparaginase administered during the induction or the type of maintenance (with or without a monthly administration of IV 6-mercaptopurine) did not influence the treatment difference either (data not shown). The treatment difference in terms of time to CNS relapse was not significant $(P=.29)$ (Fig 2). The actuarial cumulative 6-year CNS relapse rate was $12.0 \%(\mathrm{SE}=1.9 \%)$ in arm $\mathrm{A}$ and $8.6 \%(\mathrm{SE}=1.6 \%)$ in arm $\mathrm{B}$. The estimated hazards ratio was 0.76 and the $95 \%$ confidence interval was quite large ( 0.46 to 1.26$)$ as the total number of CNS relapses was relatively low. In ALL and LL, the overall 6-year CNS relapse rates were $10.8 \%(\mathrm{SE}=1.3 \%)$ and $5.6 \%(\mathrm{SE}=$ $2.8 \%$ ), respectively. The duration of survival was not significantly different $(P=.55)$ between the two treatment groups, as shown in Fig 3. The estimated 6-year survival rates were practically identical in each arm, $83.5 \%$ (SE = $2.2 \%$ ) versus $84.0 \%(\mathrm{SE}=2.0 \%)$, the estimated hazards ratio was 1.12 , and the $95 \%$ confidence interval was 0.77 to 1.63. These later numbers remained unchanged by performing an adjustment by disease. The 6-year survival of ALL

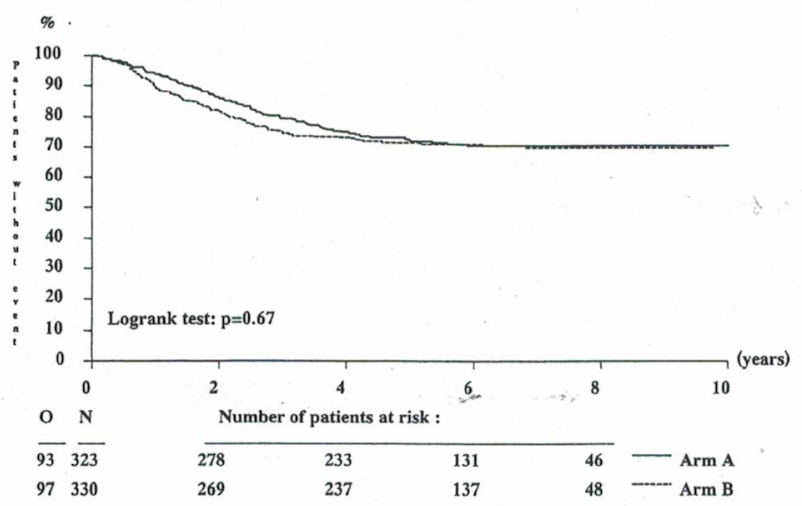

Fig 1. Disease-free survival according to arm A or arm B. Abbreviations: $O$, observed number of events (relapses or deaths in $C R$ ); $N$, number of patients at risk.

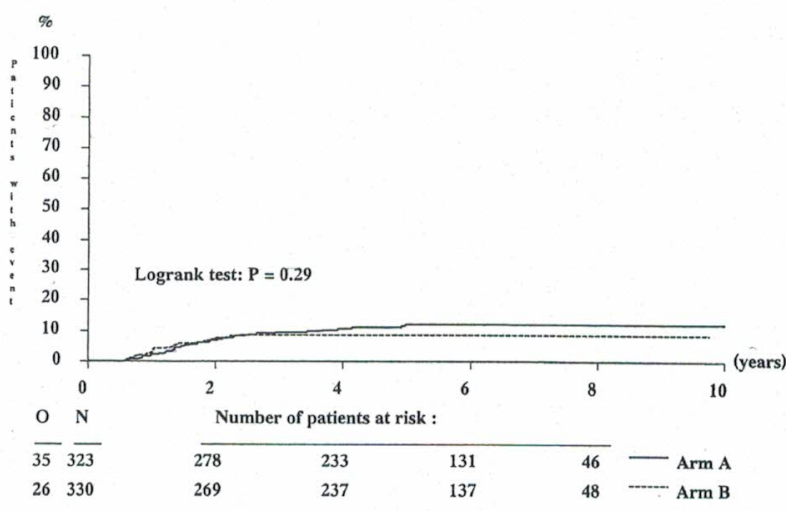

Fig 2. Cumulative risk of CNS relapse according to arm A or arm B. Abbreviations: $\mathrm{O}$, observed number of events (CNS relapse, either isolated or combined with other sites); $\mathrm{N}$, number of patients at risk.

patients was $84.1 \%(\mathrm{SE}=1.5 \%)$ versus $79.9 \%(\mathrm{SE}=$ $5.5 \%$ ) for LL patients.

\section{Protocol Compliance and Toxicity}

In $\operatorname{arm} \mathrm{A}$, all but six patients $(2 \%)$ did not receive Ara-C during the interval therapy, whereas in arm B, Ara-C was not administered to 11 patients $(3 \%)$, and in nine cases the doses of Ara-C could not be checked, as the forms were not available. The toxic side effects occurring during the interval therapy in the two treatment groups are listed in Table 4. In most cases, the toxicity was absent or only mild to moderate (grade 1 to 2 ). The incidence and the degree of infections and of increased serum creatinine levels were similar in the two treatment groups. Increased serum transaminase levels were slightly higher in arm B than in arm $\mathrm{A}\left(\chi^{2}\right.$ for linear trend, $\left.P=.12\right)$. The incidence of neurotoxicity was rare in the two arms (less than 1\%). Twenty-eight courses of reduced dose of Ara-C were administered in 16 patients because of hematologic toxicity.

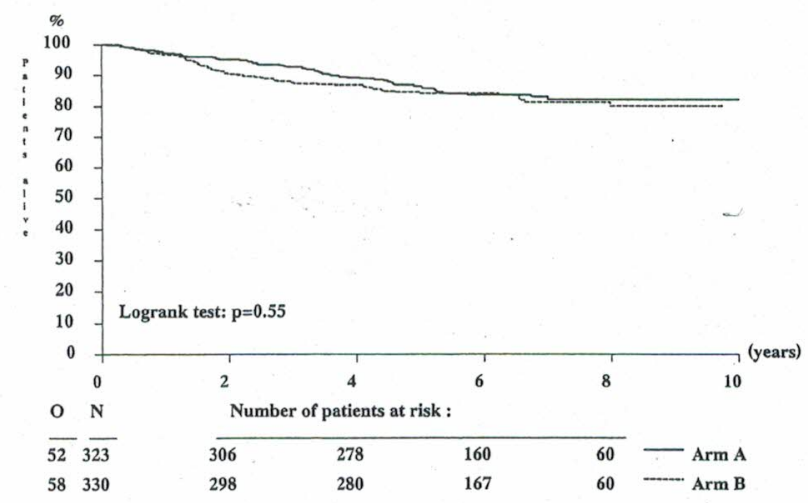

Fig 3. Survival according to arm $A$ or arm $B$. Abbreviations: $O$, observed number of deaths, whatever the cause; $N$, number of patients at risk. 
Table 4. Toxic Side Effects (WHO grading) Reported During the Interval Table 4. Therapy* According to the Randomized Arm
Tox

\begin{tabular}{|c|c|c|c|c|}
\hline & \multicolumn{2}{|c|}{$\begin{array}{c}\text { Arm A } \\
\text { (without Ara-C) } \\
(n=311)\end{array}$} & \multicolumn{2}{|c|}{$\begin{array}{c}\text { Arm B } \\
\text { (with Ara-C) } \\
(n=315)\end{array}$} \\
\hline & $\begin{array}{l}\text { No. of } \\
\text { Patients }\end{array}$ & $\%$ & $\begin{array}{l}\text { No. of } \\
\text { Patients }\end{array}$ & $\%$ \\
\hline \multicolumn{5}{|l|}{ Infection } \\
\hline Grade 1-2 & 72 & 23 & 87 & 28 \\
\hline Grade 3-4 & 8 & 3 & 14 & 4 \\
\hline \multicolumn{5}{|c|}{$\begin{array}{l}\text { Grade } 3-4 \\
\text { Increase of transaminases }\end{array}$} \\
\hline Grade 1-2 & 95 & 30 & 105 & 37 \\
\hline Grade 3-4 & 6 & 2 & 12 & 4 \\
\hline \multicolumn{5}{|l|}{$\begin{array}{r}\text { Grade 3-4 } \\
\text { Neurotoxicity }\end{array}$} \\
\hline Grade 1-2 & 17 & 5 & 18 & 6 \\
\hline Grade 3-4 & 3 & 1 & 0 & 0 \\
\hline \multicolumn{5}{|c|}{$\begin{array}{l}\text { Grade 3-4 } \\
\text { Increase of creatinine }\end{array}$} \\
\hline Grade 1-2 & 55 & 18 & 63 & 20 \\
\hline Grade 3-4 & 4 & 1 & 3 & 1 \\
\hline
\end{tabular}

*Patients with the documented forms received were included in this analysis.

The duration of interval therapy was statistically longer (Wilcoxon test, $P=.0001$ ) for patients randomized in arm B (the quartiles $50 \%, 75 \%$, and $90 \%$ were 55 days, 56 days, and 61 days, respectively) than for those in arm B (the quartiles $50 \%, 75 \%$, and $90 \%$ were 55 days, 60 days, and 68 days, respectively). The rate of patients with a prolonged interval therapy exceeding the normal 8 -week period was $33 \%$ in $\operatorname{arm} \mathrm{B}$ versus $17 \%$ in $\operatorname{arm~A}\left(\chi^{2}\right.$ test, $\left.P<.001\right)$.

\section{DISCUSSION}

Cranial irradiation may induce neuropsychologic and neuroendocrinologic damages, especially in young children, and secondary brain tumors. ${ }^{20,21}$ Previous trials have indicated that intermediate and HD IV infusion of MTX and/or IT injection of chemotherapy may replace prophylactic CNS radiotherapy without compromising efficacy in children with ALL. ${ }^{1,22}$ In the EORTC 58832 randomized trial, we demonstrated that the omission of cranial irradiation did not influence the risk of CNS relapse or the treatment outcome in intermediate and high-risk patients. ${ }^{23}$ The combination of IV $1 \mathrm{~g} / \mathrm{m}^{2}$ MTX and IT MTX injections has been shown to be as effective as cranial irradiation in preventing CNS relapse in children with favorable-risk ALL. ${ }^{1}$ Interestingly, use of IV intermediate- or high-dose MTX in patients with B-cell progenitor has been reported to prolong CR duration and to prevent leukemic relapse in the testes. ${ }^{22,24}$ Theoretically, administration of IV HD MTX may provide control of CNS sanctuary sites, because cytotoxic levels of the drug can be achieved in CSF in leukemic patients. ${ }^{25}$ However, we reported in a previous study that patients who achieve adequate MTX level in CSF at the end of a 24-hour infusion of $5 \mathrm{~g} / \mathrm{m} 2$ MTX do not seem to be protected against CNS relapse. ${ }^{26}$

Results of previous studies have indicated that cranial irradiation can be omitted in intermediate-risk ALL as well. Conter et $\mathrm{al}^{2}$ have shown that HD MTX with extended intrathecal chemotherapy is effective for protection from CNS relapse in children receiving intensive chemotherapy. Tubergen et $\mathrm{al}^{27}$ demonstrated that the frequency of CNS isolated relapses is strongly influenced by the intensity of the systemic therapy in patients with intermediate-risk ALL in which cranial irradiation is omitted. A lower rate of CNS isolated relapse was observed in patients receiving the more intensive therapy regimens. Standards are less established for combined-site CNS relapse prevention.

The reasons for testing the effect of the combination of IV MTX and Ara-C in the present study were based on experimental and pharmacokinetic data. In vitro studies indicated that these drugs act synergically against L1210 murine leukemic cells. ${ }^{7}$ This synergistic effect results from increased intracellular accumulation of Ara-C and enhancement of phosphorylation of Ara-C to its active metabolite in leukemic cells exposed to MTX. However, some studies do not find synergism. ${ }^{28}$ In vitro synergistic cell kill requires that MTX administration precede Ara-C administration and that the concentration of MTX be high $\left(1 \times 10^{-6} \mathrm{~mol}\right.$ or greater), indicating that dose and schedule of administration of these two drugs are critical. ${ }^{7}$ Moreover, pharmacokinetic and clinical studies have demonstrated that IV administration of HD Ara-C provides a high degree of penetration of the drug in the CSF with prolonged cytotoxic concentrations. ${ }^{8,9}$ We previously reported that administration of HD Ara-C in combination with HD MTX did not seem to modify the CSF MTX concentrations in a study conducted in 114 children with ALL. ${ }^{26} \mathrm{HD}$ IV Ara-C was reported to be effective in patients with meningeal leukemia. ${ }^{29}$ Very few data are available concerning the use of HD MTX in combination with Ara-C as CNS prophylactic measure in patients with ALL. Cortes et $\mathrm{al}^{30}$ reported CNS relapses in 3\% of 92 adults with ALL receiving high-dose systemic chemotherapy (MTX $1 \mathrm{~g} / \mathrm{m}^{2}$ and Ara-C $12 \mathrm{~g} / \mathrm{m}^{2}$ ) with IT injection chemotherapy as CNS prophylactic measure. A pilot study of the Pediatric Oncology Group reported a tolerable toxicity and a low incidence $(3 \%)$ of CNS relapse in nonirradiated children with standard- and poor-risk Bprecursor cell ALL receiving three-drug IT therapy and combination of IV MTX $\left(1 \mathrm{~g} / \mathrm{m}^{2}\right)$ and IV Ara-C $\left(1 \mathrm{~g} / \mathrm{m}^{2}\right)$ after documentation of $\mathrm{CR}^{31}$ In a randomized trial, this group demonstrated that patients receiving six pulses of similar treatment with IV MTX and Ara-C administered every 3 weeks have the same CR duration but higher CNS 
toxicity than those who received this combination every 12 weeks. ${ }^{32}$ Of the 428 patients with standard- and poor-risk B-precursor cell ALL of this study, 4.2\% developed isolated CNS relapse. The same group reported that RBC MTX concentrations were lower in low-risk children receiving intermediate dose of MTX in combination with Ara-C than in patients receiving MTX alone. ${ }^{33}$ In this study, lower RBC MTX concentration was associated with a worse event-free survival, suggesting that Ara-C altered MTX pharmacology in the therapeutic schedule used.

In the present study, the $5.6 \%$ incidence rate of isolated CNS relapse in children receiving HD MTX alone during interval therapy is comparable to the rate $(3.3 \%)$ observed in those receiving combination of HD MTX and Ara-C. These rates are within the range usually accepted as demonstrating efficacy for any regimen of CNS prophylaxis in children with increased-risk ALL. ${ }^{4.5}$ Recently, the BFM group reported isolated CNS relapses in $0.8 \%$ of medium-risk children receiving a reduced (12 Gy) prophylactic cranial irradiation. ${ }^{34}$ In the present study, the addition of HD Ara-C did not reduce the systemic marrow relapse rate and did not result in a significant advantage in terms of general outcome. The DFS in our two treatment groups of patients compares favorably with those achieved in studies with BFM-based regimens. ${ }^{2,4,5}$ It is noteworthy that the current report included patients with high leucocyte count, T-ALL, or lymphomatous features that were reported to have a worse prognosis. ${ }^{35,36}$

The duration of interval therapy was statistically longer for patients receiving $\mathrm{HD}$ Ara-C, indicating that courses of MTX and Ara-C were more frequently delayed than courses of MTX alone. Toxic events such as infections and abnormal transaminases levels, which were more frequent in this treatment group, could explain the delay in treatment realization. Interestingly, the addition of $\mathrm{HD}$ Ara-C to HD MTX did not enhance the neurotoxicity of this drug. We previously reported that children receiving HD Ara-C during interval therapy did not exhibit impairment of biogenic amines metabolites concentrations in CSF (abnormalities of these biochemical compounds being reported in some patients with MTX-induced neurotoxicity). ${ }^{37}$

In conclusion, the addition of HD Ara-C to HD MTX could not provide better protection of CNS relapse and less systemic relapses as compared with HD MTX alone in children with increased-risk ALL or stage III and IV lymphoblastic lymphoma.

\section{REFERENCES}

1. Abromowitch M, Ochs J, Pui CH, et al: Efficacy of high-dose methotrexate in childhood acute lymphoblastic leukemia: Analysis by contemporary risk classification. Blood 71:866-869, 1988

2. Conter V, Arico M, Valsecchi MG, et al: Extended intrathecal methotrexate may replace cranial irradiation for prevention of CNS relapse in children with intermediate-risk acute lymphoblastic leukemia treated with Berlin-Frankfurt-Munster-based intensive chemotherapy. J Clin Oncol 13:2497-2502, 1995

3. Tsurusawa M, Katano N, Yamamoto Y, et al: Improvement in CNS protective treatment in non-high-risk childhood acute lymphoblastic leukemia: Report from the Japanese Children's Cancer and Leukemia Study Group. Med Pediatr Oncol 32:259-266, 1999

4. Kamps WA, Bokkerink JPM, Halhen K, et al: Intensive treatment of children with acute lymphoblastic leukemia according to ALL-BFM 86 without radiotherapy: Results of Dutch Childhood Leukemia Study Group protocol ALL-7 (1988-1991). Blood 94:1226-1236, 1999

5. Reiter A, Schrappe M, Ludwig WD, et al: Chemotherapy in 998 unselected childhood acute lymphoblastic leukemia patients: Results and conclusions of the multicenter trial ALL-BFM 86. Blood 84:31223133, 1994

6. Edelstein M, Vietti TJ, Valeriote F: The enhanced cytotoxicity of combinations of 1-beta- D arabinofuranosylcytosine and methotrexate. Cancer Res 35:1555-1558, 1975

7. Cadman E, Eiferman F: Mechanism of synergistic cell killing when methotrexate precedes cytosine arabinoside. J Clin Invest 64:788797, 1979

8. Morra E, Lazzarino M, Inverardi D, et al: Systemic high-dose ara-C for the treatment of meningeal leukemia in adult lymphoblastic leukemia and non-Hodgkin lymphoma. J Clin Oncol 4:1207-1211, 1986
9. Slevin M, Piall E, Aherne G, et al: Effect of dose and schedule on pharmacokinetics of high-dose cytosine arabinoside in plasma and cerebrospinal fluid. J Clin Oncol 1:546-551, 1983

10. Murphy SB: Classification, staging and end results of treatment in childhood non-Hodgkin's lymphoma: Dissimilarities from lymphomas in adults. Semin Oncol 7:332-339, 1980

11. Benett JM, Catovsky D, Daniel MT, et al: Proposals for the classification of the acute leukemias. Br J Haematol 33:451-458, 1976

12. The Non-Hodgkin's Lymphoma Pathologic Classification Project: National Cancer Institute sponsored study of classification on non-Hodgkin's Lymphoma: Summary and description of a working formulation for clinical usage. Cancer 49:2112-2135, 1982

13. Harris NL, Jaffe ES, Stein H, et al: A revised EuropeanAmerican classification of lymphoid neoplasm: A proposal from the international lymphoma study group. Blood 84:1361-1392, 1994

14. Linder J, Ye Y, Harrington D, et al: Monoclonal antibodies marking $\mathrm{T}$ lymphocytes in paraffin-embedded tissue. Am J Pathol $127: 1-9,1987$

15. Linder J, Ye Y, Armitage JO, et al: Monoclonal antibodies marking B lymphocytes in paraffin-embedded tissue. Mod Pathol 1:29-35, 1988

16. First MIC Cooperative Study Group: Morphologic, immunologic and cytogenetic (MIC) working classification of acute lymphoblastic leukemia. Cancer Genet Cytogenet 23:189-197, 1986

17. Miller AB, Hoogstraten B, Staquet M, et al: Reporting results of cancer treatment. Cancer 47:207-214, 1981

18. Buyse ME, Staquet MJ, Sylvester RJ (eds): Cancer Clinical Trials: Methods and Practice. Oxford, England, Oxford Medical Publication, 1984, pp 361-406 
1942

19. Cox DR, Oakes D: Analysis of survival data. New York, NY, Chapman and Hall, 1984

20. Packer RJ, Meadows AT, Rorke LB, et al: Long term sequelae of cancer treatment on the central nervous system in childhood. Med Pediatr. Oncol 15:241-253, 1987

21. Jankovic M, Brouwers P, Valsecchi MG, et al: Association of adiation with intellectual function in children with 1800 cGY choblastic leukemia. Lancet 344:224-227, 1994

22. Pullen J, Boyett J, Shuster J, et al: Extended triple intrathecal ( $\mathrm{CNS}$ relapse in good-risk and chemotherapy trial for prevention of CNe lymphoblastic leukemia: A poor-risk patients with B-progenitor acu Oncol 11:839-849, 1993 Pediatric Oncology Group study.

23. Vilmer E, Suciu S, Ferster A, et al: Long termood acute lymphorandomized trials $(58831,58832,58881)$ in childhood acute (in press) .

24. Abromowitch M, Ochs J, Pui CH, en aly lymphoblastic leukemia: improves clinical outcome in children with acut Oncol 16:297-303, 1988 St Jude Total Therapy Study X. Med Pediat Ont leukemia with larges

25. Hryniuk WN, Bertino JR: Treat Clinical-biochemical correlates. doses of methotrexate and folinic acid

J Clin Invest 48:2140-2155, 1969 F, et al: Cerebrospinal fluid drug

26. Millot $\mathrm{F}$, Rubie $\mathrm{H}$, Mazingue $\mathrm{F}$, et al. Ceus $5 \mathrm{~g} / \mathrm{m}^{2}$ methotrexate. levels of leukemic children receiving

Leuk Lymphoma 14:141-144, 1994 'Brien RT, et al: Prevention of

27. Tubergen DG, Gilchrist GS, O'Brien RT, et al: Peukemia: Com-

CNS disease in intermediate-risk acute lympthecal methotrexate and the parison of cranial radiation and intrathecal mencer Group report. importance of systemic therapy

J Clin Oncol 11:520-526, 1993 Jynergistic and antagonistic interactions of methotrexate and 1-beta-D-arabinofuranosyl
29. Frick J, Ritch PS, Hansen RM, et al: Successful treatment of ente systemic high-dose cytosine arabinoside. J Clin Oncol 2:365-368, 1984

30. Cortes J, O'Brien SM, Pierce S, et al: The value of high-dose chemotherapy and intrathecal therapy for central nervous system prophylaxis in different risk groups of adults acute lymphoblas89:2091-2097, 1995

(1.

the arabinoside, spread out of intermediate-dose methotrexate and children with non- $\mathrm{T}$ non-B acute or up front, in combination therapy for children with 1991

lymphoblastic leukemia. Cancer 67:550 $\mathrm{Y}$, et al: Comparison of two

32. Land VJ, Shuster JJ, Ravindranath schedules of intermediate-dose methotrexate and lymphoblastic leukemia: A therapy for childhood B-precursor cell acute lym 12:1939-1945, 1994

Pediatric Oncology Group study. J Clin Oncol 12: Changes in red blood

33. Graham ML, Shuster JJ, Kamen BA, et al. Chact on outcome when cell methotrexate pharmacology and their in the treatment of acute cytarabine is infused with methotrexate in the treatogy Group study. lymphocytic leukemia in children: A

Clin Cancer Res 2:331-337, 1996 wig WD, et al: Improved outcome in

34. Schrappe M, Reiter A, Ludwig WD, etal. Inproved ouse of anthrachildhood acute lymphoblastic leukemia de trial ALL-BFM 90. Blood cyclines and radiotherapy: Results of the trial ALL-BP 95:3310-3322, 2000

35. Smith M, Arthur D, Camitta B, et al: Uniform approach to risk , Achildren with acute lymclassification and tiea. J Clin Oncol 14:18-24, 1996

phoblastic leukemia. J Clin Oncol Bleyer WA, et al: Lymphomatous 36. Steinhertz PG, Siegel SE, Bleyer WA, A subgroup at high presentation of childhood lymphoblasti 68:751-758, 1991

risk of early treatment failure. Cancer $68: 75$, et al: Changes of cerebral biopterin

37. Millot F, Dhondt J, Mazingue F, et al: Changes of ceen receiving 5 and biogenic amine metabolism in leukemic children recivin $\mathrm{g} / \mathrm{m}^{2}$ intravenous methotrexate. Pediatr Res 37:151-154, 1995 